\title{
Asthma control in adolescents: role of leukotriene inhibitors
}

This article was published in the following Dove Press journal:

Adolescent Health, Medicine and Therapeutics

4 October 2010

Number of times this article has been viewed

\section{Stavroula Giavi Nikolaos G Papadopoulos \\ Allergy Department, Second Pediatric Clinic, University of Athens, Athens, Greece}

\begin{abstract}
Asthma is a chronic inflammatory disease of the airways and is a big burden worldwide. It affects both children and adults, but it is insufficiently studied in adolescents, although this age group has important peculiarities and is challenging to treat, due to, but not exclusively because of, lack of adherence to treatment instructions. Evidence-based guidelines for the treatment of asthma targeting specifically adolescents are lacking, due to the fact that most studies are conducted either on children or in adults. Exercise-induced asthma occurs commonly in adolescents, leading to impaired physical activity. This review describes current treatment options for asthma in adolescents, focusing on leukotriene receptor antagonists, both as a monotherapy and as an add-on therapy for optimal asthma control.

Keywords: asthma control, adolescent, leukotriene antagonists, montelukast, exercise-induced asthma
\end{abstract}

\section{Introduction}

Asthma is a chronic inflammatory disease of the airways that affects a large proportion of the population, especially in developed countries. Although a standard definition has been difficult to reach, the use of standardized methods for assessing the prevalence and wheezing illness in children and adults has led to an asthma prevalence estimation in the range of $1 \%-18 \%$ of the global population. There is evidence that between-country differences are now less, particularly in the age group 13-14 years, resulting from a decreasing or stabilizing trend in North America and Western Europe and a continuing increase in regions where prevalence was previously low. ${ }^{1-3}$ Asthma may limit ordinary activities, affect quality of life, and can sometimes be fatal. When uncontrolled, it increases health care costs, decreases productivity, and reduces participation in family life. ${ }^{2}$

\section{Asthma in adolescents}

Asthma among adolescents is insufficiently studied, although (or perhaps due to the fact that) adolescents are a particularly challenging patient population, in part because of the rapid physical and emotional development that takes place during this stage of life, and in part because of their unique attitude to chronic illnesses and their therapies. ${ }^{4}$ Another important issue is that they are a population group that exercises regularly, and many elite athletes belong to this particular population. Exercise-induced bronchoconstriction (EIB) ${ }^{5}$ and exercise-induced asthma (EIA) occur commonly in adolescents, but have not been studied extensively. If not properly controlled, asthma can become a reason for discontinuation of sport practicing, causing negative emotions.
Correspondence: Stavroula Giavi Allergy Department, Second Pediatric Clinic, University of Athens,

4I Fidippidou,

Athens 115 27, Greece

Tel +302107776964

Fax +30210777 7693

Email stagial4@otenet.gr 
Although EIB is considered a fairly common condition, its estimated frequency depends on the population under study and the methods used to detect it. For example, the prevalence of EIB is greater than $90 \%$ in patients with (uncontrolled) persistent asthma, 30\%-70\% in elite athletes, ${ }^{5}$ and $5 \%-20 \%$ in the general population. ${ }^{6}$

Adherence to treatment and scheduled visits to the doctor are the most demanding issues the clinician faces with asthmatic adolescents. Good clinical practice, flexible visit schedules, easy-to-use medications with a quick onset of action and minimal side effects, as well as alternative strategies in case of treatment failure, have to be in mind when dealing with adolescents. Nonadherence to the most potent therapy can in fact be equivalent to no therapy at all. Furthermore, it is clear that efficacy in clinical trials may be different from effectiveness in the real world. In practice, compliance with chronic asthma regimens, which is a major determinant of effectiveness, may be complicated by dosing frequency, side effects or fear of side effects, medication cost, effectiveness of patient education, perceived onset of action, and difficulty with inhaler devices. Indeed, clinical studies have demonstrated that poor adherence to asthma controller medication increases the need for oral steroid rescue. ${ }^{7}$

\section{Consequences of uncontrolled asthma}

It has been shown that children and adolescents who experience nocturnal asthma awakenings 1-3 days per week are more likely to miss school, compared with those who do not have nocturnal awakenings. ${ }^{8}$ Asthma-associated effects on school attendance are consistently found, whether absences are identified through school records $s^{8-10}$ or self-report. ${ }^{11}$ In addition, children with uncontrolled asthma, although present at school, may not be able to perform at their best. The impact of asthma on quality of life and productivity depends on the patient's level of asthma control. Schmier et al evaluated the impact on health outcomes in 239 patients (131 young children and 108 adolescents) with asthma who were controlled versus inadequately controlled. ${ }^{12}$ Adolescent asthmatic patients completed validated questionnaires, including the Asthma Control Test, ${ }^{13}$ the Pediatric Asthma Quality of Life Questionnaire, ${ }^{14}$ subscales of the Health and Work Questionnaire, ${ }^{15}$ and several items about the impact of asthma on their school or work activities in the past week. Adolescents with inadequately controlled asthma, compared with those having controlled disease, demonstrated significantly higher levels of impairment in four domains of the Pediatric Asthma Quality of Life Questionnaire. Because more than one-third of adolescents with inadequately controlled asthma report missing one day of school due to asthma in the past week, the implications for missing school during the year are considerable. It is unknown whether the same students consistently miss school due to asthma or if a typical student misses a day every few weeks, but either scenario demonstrates an important interruption in the educational process.

\section{Controller medications for adolescents}

International guidelines encourage a stepwise approach to asthma treatment with the aim of gaining control, abolishing symptoms, and optimizing lung function parameters. Antiinflammatory controller therapy for the long-term treatment of persistent asthma is recommended. Regular inhaled corticosteroids (ICS) and "as needed" inhaled short-acting $\beta_{2}$-agonists (SABAs) are the cornerstones of therapy. Evidence-based guidelines for the treatment of asthma specifically targeting adolescents are lacking, due to the fact that most studies are conducted either on children or in adults. Data for adolescents exist only as a subgroup of other studies, so this must be taken into consideration before drawing conclusions. The PRACTALL (Practical Allergy) consensus report suggests that asthma phenotypes should be characterized according to age and triggers, including a "teenager group" as a distinct phenotype. ${ }^{16}$ PRACTALL focuses on this age group, pointing out that adolescents are more reluctant to use regular daily medications and wish to have no restrictions to their lives. Smoking can be a big issue, and unwillingness to visit a pediatrician because they are in a transition period may cause problems in controlling asthma optimally.

\section{Inhaled corticosteroids}

The evidence demonstrates rapid clinical and lung function improvement with low doses of ICS (eg, 100-200 $\mu \mathrm{g}$ budesonide daily) in most cases of mild asthma, especially when treatment starts in the early course of the disease. ${ }^{17-19}$ Symptom control and improvement in lung function is achieved within 1-2 weeks, although higher doses and longer periods of treatment are occasionally needed for maintenance of the results. When ICS are discontinued, deterioration of asthma control occurs within weeks or months. ${ }^{20}$ Their action is limited by their mode of administration, which may be difficult for children, even for adolescents, and by potential long-term tolerability concerns, such as linear growth delay. Systemic effects have been reported at high doses but studies are not conclusive, because the side effects of budesonide were 
limited to a small transient reduction of growth velocity. ${ }^{20}$ A meta-analysis of the effect of ICS on the linear growth of children with asthma was published in 2000. The metaanalysis suggests that moderate doses of beclomethasone and budesonide in children and adolescents with mild to moderate asthma cause a decrease in linear growth velocity of $1.51 \mathrm{~cm} /$ year and $0.43 \mathrm{~cm} /$ year, respectively. Additionally, whether inhaled steroids in doses presently used in children with asthma affect final adult height remains unanswered. If ICS are required for the control of asthma in a child, then careful monitoring of height, and the lowest possible effective dose would be appropriate to minimize any potential negative effect on growth. ${ }^{21}$

\section{Long-acting $\beta_{2}$-agonists}

Long-acting $\beta_{2}$-agonists (LABAs) are primarily used as an add-on therapy in children older than five years, whose asthma is insufficiently controlled by low or medium doses of ICS or as single-dose therapy before vigorous exercise. Improvement of lung function measurements has been shown in most studies. ${ }^{22-25}$ However, with daily therapy, the duration of protection may be reduced due to tachyphylaxis, but is still longer than that provided by SABAs. ${ }^{26}$

As a rule, monotherapy with LABAs must be avoided, because these agents may increase the risk for fatal and nonfatal asthma exacerbations as shown in a meta-analysis where risks were similar for children and adults, including adolescents as well. ${ }^{27}$

Fixed combinations of an ICS and a LABA are preferred to the drugs being administered in separate devices. In this way, fixed combination inhalers ensure the early use of ICS.

\section{Anti-lgE}

Anti-IgE (omalizumab) is a treatment option limited to patients with elevated levels of serum IgE and detectable specific IgE for clinically relevant aeroallergens. Its current indication is for patients with severe allergic asthma who are uncontrolled with high-dose ICS, although the dose of concurrent treatment has varied in different studies. Improved asthma control is reflected by fewer symptoms, less need for reliever medications, and fewer exacerbations. ${ }^{28-30}$ Massanari et al evaluated the effectiveness of omalizumab in adolescents with moderate to severe allergic asthma, inadequately controlled with ICS. Data were collected from patients aged 12-17 years, pooled from five placebo-controlled registration trials of omalizumab. Addition of omalizumab decreased mean numbers of rescue drugs versus placebo, improved asthma symptom scores, and reduced unscheduled office visits. ${ }^{31}$

\section{Leukotriene receptor antagonists}

Cysteinyl leukotrienes, produced via the 5-lipoxygenase pathway, are important inflammation mediators in asthma. They not only induce smooth muscle contraction and bronchoconstriction, but also promote eosinophilic inflammation. ${ }^{32}$ They are released in asthmatic airways after exposure to allergens. Cooling and drying of the airways appear also to promote the generation of leukotrienes, which then produce bronchoconstriction, suggesting that leukotrienes might participate in the pathogenesis of both exerciseinduced and cold air-induced asthma. ${ }^{33-35}$

The activity of the leukotriene pathway can be blocked in two ways, ie, by inhibition of synthetic enzymes and by mediator receptor blockade. Zileuton $\left(Z^{2} f l{ }^{\circledR}\right)$ is a 5-lipoxygenase inhibitor used mainly in the US, that selectively inhibits the 5-lipoxygenase enzyme, suppressing consequently the formation of 5-lipoxygenase products (LTB4, LTC4, LTD4, and LTE4). Montelukast (Singulair ${ }^{\circledR}$ ), zafirlukast (Accolate $\left.{ }^{\circledR}\right)$, and pranlukast $\left(\right.$ Ono $^{\circledR}$, used mainly in Japan) are potent and highly selective antagonists of Type I cysteinyl leukotriene receptors, with affinities approximately two-fold greater than the natural ligand. They are an important class of nonsteroidal antiasthma therapy, in that they are effective over a wide range of asthma severity and phenotypes, with a high therapeutic index and oral activity. They have both anti-inflammatory and bronchodilator effects (antagonism of leukotriene-induced smooth muscle bronchoconstriction). ${ }^{36-38}$

There are few data available specifically for adolescents, and are mainly on montelukast. Most of the literature has either a mixed population of children and adolescents, or of adolescents and adults, presenting results that cannot accurately characterize the adolescent population specifically. Such studies are described in the following text.

\section{Montelukast for chronic asthma}

Several studies have shown that montelukast is effective in children and adults. ${ }^{39-41}$ The efficacy of montelukast for the improvement of lung function in children aged 6-14 years was established in $1999^{42,43}$ in a double-blind study comparing the clinical effect of oral montelukast $5 \mathrm{mg}$ once daily with placebo in children with asthma. The montelukast group showed an increase of $8.23 \%$ from baseline in forced expiratory volume in one second $\left(\mathrm{FEV}_{1}\right)$ versus $3.58 \%$ in the placebo group. Spahn et al randomized 21 children, mostly adolescents aged 9-18 years with mild to moderate asthma to receive either montelukast 5 or $10 \mathrm{mg}$ or placebo for eight weeks, and examined peripheral airway obstruction as 
measured by lung volumes, air trapping, airway resistance, and specific conductance. Symptoms and albuterol use were recorded twice daily, and exhaled nitric oxide, forced oscillometry, spirometry, and body box plethysmography were performed at randomization, and at weeks 2, 4, 6, and 8 . Circulating eosinophil counts and endothelial progenitor cells were measured at randomization and at week 8 . Montelukasttreated patients had lower residual volumes $(P=0.05)$, residual volume-total lung capacity ratio $(P=0.04)$, and raw $(P=0.02)$ and serum endothelial progenitor cells at week 8 compared with those treated with placebo. Montelukast therapy was associated with less air trapping, hyperinflation, airway resistance, and specific conductance. ${ }^{44}$

\section{Montelukast versus ICS for control of mild asthma}

The Montelukast Study of Asthma in Children (MOSAIC) was a 12-month, multicenter, double-blind, noninferiority trial to determine the effect of once-daily, orally administered montelukast $5 \mathrm{mg}$, compared with twice-daily inhaled fluticasone $100 \mu \mathrm{g}$, on the percentage of asthma rescue-free days (any day without asthma rescue medication and with no asthma-related resource use), among patients 6-14 years of age (adolescents included) with mild persistent asthma. ${ }^{45}$ Although the fluticasone treatment group showed a significantly better percentage of $\mathrm{FEV}_{1}$, days with $\beta$-receptor agonist use, and better quality of life than the montelukast treatment group, montelukast was demonstrated to be not inferior to fluticasone in increasing the percentage of rescuefree days among those children. The mean percentage of asthma rescue-free days was $84 \%$ in the montelukast group and $86.7 \%$ in the fluticasone group. The study was not placebo-controlled.

The Pediatric Asthma Controller Trial (PACT), sponsored by the National Heart, Lung and Blood Institute in the US, was an independently-funded, randomized, controlled study published in January 2007. ${ }^{46}$ It included 285 children aged 6-14 years, and compared three different asthma treatments. The subjects were randomized to one of three 48-week treatments, ie, inhaled fluticasone $100 \mu \mathrm{g} \times 2$, combined inhaled fluticasone $100 \mu \mathrm{g} \times 2$ plus salmeterol $50 \mu \mathrm{g} \times 2$ (combination therapy), and montelukast monotherapy $5 \mathrm{mg} \times 1$ orally. The study was designed to compare the effectiveness of the three regimens in achieving asthma control, with asthma control days as the primary outcome. Fluticasone monotherapy and combination therapy achieved greater improvements in asthma control days than montelukast. Growth over 48 weeks was similar in all age groups.
The response to asthma treatment appears to be variable, in that asthmatic children who do not respond to ICS may respond to montelukast and vice versa. ${ }^{47,48}$ A study that points to the importance of the different drug categories for asthma treatment is CLIC (Characterizing the response to a Leukotriene Receptor Antagonist and an inhaled Corticosteroid), which was supported by the National Heart, Lung and Blood Institute, and the first independently-funded, controlled study comparing the efficacy of ICS and montelukast. CLIC included children aged 6-17 years with mild to moderate asthma. The results of the main outcome $\left(\mathrm{FEV}_{1}\right)$ were published in February $2005^{47,48}$ and those of the secondary outcomes in January 2006. ${ }^{47}$ Subjects were randomized to two crossover sequences, ie, eight weeks of an ICS and eight weeks of montelukast, and response was assessed on the basis of improvement in $\mathrm{FEV}_{1}$ and asthma-associated biomarkers. It was shown that if response was defined as an improvement in $\mathrm{FEV}_{1}$ of $\geq 7.5 \%, 17 \%$ of 126 participants responded to both medications, $23 \%$ responded to fluticasone alone, 5\% responded to montelukast alone, and 55\% responded to neither medication. When comparisons were performed for average values, fluticasone was significantly more effective in most asthma control measures; nevertheless, this reflected the distribution of individuals as described above, rather than a uniform response. When asthma control days were used as an outcome, higher baseline FeNO levels, greater salbutamol use, and more positive aeroallergen skin test responses, in addition to fewer asthma control days at baseline, predicted more asthma control days after fluticasone treatment. A favorable response to montelukast alone was associated with higher urine LTE4 levels, younger age, and shorter disease duration. No difference in adherence to medications was found, but dropouts were more common in the montelukast group. The authors concluded that asthma therapy may soon move from the current approach based on mean responses in populations to one in which the treatment that is the most likely to produce a favorable response rapidly as identified for each individual patient on the basis of her or his phenotypic and, possibly genotypic, characteristics. Again, we stress that the above studies refer to ages wider than adolescence, so it is possible that they may differ considerably in this population.

\section{Montelukast as an add-on therapy}

Several studies that support the effectiveness of montelukast as an add-on therapy to inhaled corticosteroids has been published, none of them having focused on adolescents alone. ${ }^{49-51}$ 
Lemanske et al randomly assigned 182 children (6-17 years of age) who suffered from uncontrolled asthma while receiving $100 \mu \mathrm{g}$ fluticasone twice daily to receive each of three blind stepup therapies in random order for 16 weeks, ie, $250 \mu \mathrm{g}$ fluticasone twice daily, $100 \mu \mathrm{g}$ fluticasone plus $50 \mu \mathrm{g}$ of a long-acting $\beta_{2}$ agonist twice daily, or $100 \mu \mathrm{g}$ fluticasone twice daily plus 5 or $10 \mathrm{mg}$ of a leukotriene receptor antagonist (LTRA) once daily. They used a triple crossover design and a composite of three outcomes (exacerbations, asthma free-days, and $\mathrm{FEV}_{1}$ ) to determine whether the frequency of a differential response to the stepup regimens was more than $25 \% .^{52} \mathrm{~A}$ differential response was assessed in 161 of $165(98 \%)$ children who were evaluated $(P<0.001)$. In pairwise comparisons, the proportion of patients who had a better response to LABA stepup was higher than the proportion with a better response to LTRA stepup ( $52 \%$ versus $34 \%, P=0.02$ ), and the proportion with a better response to ICS stepup (54\% versus $32 \%$, $P=0.004$ ), whereas the response to LTRAs and ICS stepup therapies were similar. There were no differences in the differential response according to age, whether age was examined as a dichotomous covariate (5-11 years or 12-17 years) or as a continuous covariate. Therefore, it seems that, among children and adolescents, the phenotypic variability to treatment is larger than that of age, therefore supporting the possibility of drawing conclusions for adolescents from mixed population studies.

\section{Montelukast in exercise-induced asthma}

EIA is a common asthma phenotype, and is estimated to occur in a majority of uncontrolled asthmatic patients. ${ }^{53}$ Adolescents participate in a wide range of exercise with peers. Many of them may discontinue their habit or find alternative and less demanding sports after experiencing uncomfortable symptoms during or after exercise. Inactivity as a consequence of asthma is not acceptable, ${ }^{2}$ and indicates the need for appropriate or additional controller medications so that the patient's life can be normalized as much as possible. Beneficial effects of exercise on asthma have been shown in another age group. ${ }^{54}$ Additionally, a good proportion of elite athletes are adolescents, so the need for medications to control asthma symptoms due to exercise is crucial. The intensity of exercise, as well as the type of exercise, is important in producing symptoms. Bisgaard and Szefler ${ }^{55}$ suggest that this condition in children and adolescents often remains unrecognized and can occur in patients who only wheeze following exercise. It is suspected that the repeated high ventilation required during training may irritate the airways and result in mediator release and airway injury.
A multicenter, double-blind, placebo-controlled, two-period crossover study examined the effect of montelukast in asthmatic children $(n=27)$ aged 6-14 years with a fall in $\mathrm{FEV}_{1}$ of $\geq 20 \%$ after two prerandomization exercise challenges. ${ }^{56}$ Children were administered montelukast $5 \mathrm{mg}$ /day or placebo for two days, followed by exercise challenge 20-24 hours after the last dose in each period. Montelukast significantly attenuated EIA at the end of the dosing interval.

In another placebo-controlled study, children $(n=64)$ with mild asthma had significant improvements in asthma score (25.2 versus $18.3, P<0.01)$, maximum percent fall in $\mathrm{FEV}_{1}$ after exercise (36.8\% versus $27.6 \%, P<0.01$ ), and time to recovery (43.0 versus 26.1 minutes, $P<0.01$ ) after receiving montelukast $5 \mathrm{mg}$ /day for eight weeks, while no significant improvements were observed with placebo. ${ }^{57}$

Although there is no consensus that a delayed response to exercise occurs in EIB, ${ }^{58,59}$ such a reaction has been reported in some studies. ${ }^{60,61}$ Although only five of 22 subjects (aged 7-16 years) enrolled in a small, double-blind, randomized pediatric EIB study demonstrated a late-phase response to exercise, once-daily treatment with montelukast $5 \mathrm{mg}$ for one week attenuated the immediate response and abolished the latephase response in these five subjects. This effect was independent of the use of ICS. ${ }^{62}$ Such an attenuation of both responses demonstrates that leukotrienes in the airway have more than just an immediate effect on airway smooth muscle.

The duration that a medication can attenuate EIB is also important to many athletes and patients (especially adolescents) who may exercise at different times of the day or who do not wish to take medication immediately before exercise. SABAs have been used for years to prevent the effects of exercise in patients with EIB. However, they usually have duration of effect of only 2-4 hours which may not adequately protect the individual who may wish to exercise late in the day or at school following a morning dose of medication. Studies with LABAs have shown a protective effect on EIB of 10-12 hours, ${ }^{63,64}$ which is a benefit in such situations. However, as discussed previously, tolerance is common with regular use of LABAs, resulting in a decrease in duration of protection. ${ }^{65,66} \mathrm{~A}$ three-way crossover study with montelukast, salmeterol, and placebo was performed in 47 patients aged 15-44 years with demonstrable EIB. ${ }^{67}$ $\mathrm{FEV}_{1}$ was measured at $2,8.5$, and 24 hours postdose. The results of this study showed that both montelukast and salmeterol protected against the effects of exercise at two and 8.5 hours postdose, but the protective effect of salmeterol had terminated by 24 hours. Montelukast patients still showed 
protection 24 hours post-treatment, making the drug an attractive choice for young athletes.

Response to asthma therapy appears to be variable also in EIB. ${ }^{68}$ For example, no effect was seen in a study of montelukast in the prevention of asthma-like symptoms in elite ice hockey players. ${ }^{69}$ One of the reasons patients or patient groups respond differently to a specific medication is very likely to be because of specific gene polymorphisms. Genetic studies have suggested a role of various genes of the leukotriene pathway in disease susceptibility, severity, or patient's response to antileukotriene therapy. Despite the discrepancies of the published studies, two polymorphisms in the ALOX5, and variants in genes encoding CYSLTR1 and CYSLTR2, seem likely to have a real pharmacogenetic effect with relevance to the asthma treatment response. ${ }^{70,71} \mathrm{~A}$ recent study looked at gene polymorphisms in patients with $\mathrm{EIB}^{72}$ demonstrated that Korean children with EIB had a better response to a LTRA if they had a particular polymorphism associated with leukotriene inflammation. The relevance and clinical impact of these associations needs to be investigated in larger studies. Independent of the treatment option, it is important to re-evaluate the patient with asthma or EIB, initially at 2-4 weeks because responses vary considerably.

\section{Montelukast in asthma}

\section{with concurrent allergic rhinitis}

Allergic rhinitis coexists in up to $80 \%$ of asthmatic patients. ${ }^{73}$ Inadequately controlled symptoms of rhinitis have been associated with an increased risk of an asthma attack. In a subgroup analysis of the COMPACT (Clinical Outcomes with Montelukast as a Partner Agent to Corticosteroid Therapy) study, the group of asthmatics with concomitant rhinitis benefit more from the addition of montelukast to budesonide than from the doubling of budesonide alone as a therapeutic approach. ${ }^{74}$ Studies of optimal treatment for asthma with coexisting allergic rhinitis, addressed to adolescent patients would be helpful in the future.

\section{Conclusions}

Asthma control in adolescents is important for their personal, physical, and emotional development. Participation in regular or elite exercise should not be restricted but strongly encouraged after the appropriate personalized asthma control action plan is established. Because compliance is the most important factor in this age group, effective and easy to carry and use medications are preferable in adolescents, and regular monitoring should be scheduled. Different categories of drugs can offer suitable options for adolescents according to their personal needs.

Nevertheless, the available information is inadequate to reach solid conclusions. ICS as well as LTRAs have shown efficacy in mixed populations (including either children or adults), but age-related particularities have seldom been addressed. Therefore, treatment according to general guidelines, eg, PRACTALL or GINA (Global Initiative for Asthma) should be followed. ${ }^{2,16}$ Phenotype-specific guidelines (including age and trigger as determinants) are awaited and may provide improved solutions, as in the case of EIA in which leukotriene inhibitors seem to provide optimal control.

During adolescence, major hormonal changes associated with differential expression of asthma symptoms indicate an additional factor possibly complicating treatment response. Compliance issues should be separately addressed and seriously taken into account. LTRAs have dosing and administration advantages that make them attractive options in this age group.

\section{Disclosure}

NGP has received honoraria and/or consulting fees from ALK-Abello, AstraZeneca, Merck Sharp and Dohme, GlaxoSmithKline, Novartis, Nycomed, Schering-Plough, and Union Chimique Belge, and has received research grants from AstraZeneca, Merck Sharp and Dohme, GlaxoSmithKline, and Delmedica. Stavroula Giavi declares no conflict of interest in this work.

\section{References}

1. Kroegel C. Global Initiative for Asthma (GINA) guidelines: 15 years of application. Expert Rev Clin Immunol. 2009;5:239-249.

2. Bateman ED, Hurd SS, Barnes PJ, et al. Global strategy for asthma management and prevention: GINA executive summary. Eur Respir J. 2008;31:143-178.

3. Masoli M, Fabian D, Holt S, Beasley R. The global burden of asthma: Executive summary of the GINA Dissemination Committee report. Allergy. 2004;59:469-478.

4. Collins JE, Gill TK, Chittleborough CR, Martin AJ, Taylor AW, Winefield H. Mental, emotional, and social problems among school children with asthma. J Asthma. 2008:45:489-493.

5. Parsons JP, Mastronarde JG. Exercise-induced bronchoconstriction in athletes. Chest. 2005;128:3966-3974.

6. Weiler JM, Bonini S, Coifman R, et al. American Academy of Allergy, Asthma and Immunology Work Group report: Exercise-induced asthma. J Allergy Clin Immunol. 2007;119:1349-1358.

7. Milgrom H, Bender B, Ackerson L, Bowry P, Smith B, Rand C. Noncompliance and treatment failure in children with asthma. JAllergy Clin Immunol. 1996;98:1051-1057.

8. Moonie SA, Sterling DA, Figgs L, Castro M. Asthma status and severity affects missed school days. $J$ Sch Health. 2006;76:18-24.

9. Silverstein MD, Mair JE, Katusic SK, Wollan PC, O'Connell EJ, Yunginger JW. School attendance and school performance: A populationbased study of children with asthma. J Pediatr. 2001;139:278-283. 
10. McCowan C, Bryce FP, Neville RG, Crombie IK, Clark RA. School absence - a valid morbidity marker for asthma? Health Bull (Edinb). 1996;54:307-313.

11. Diette GB, Markson L, Skinner EA, Nguyen TT, Algatt-Bergstrom P, Wu AW. Nocturnal asthma in children affects school attendance, school performance, and parents' work attendance. Arch Pediatr Adolesc Med. 2000;154:923-928.

12. Schmier JK, Manjunath R, Halpern MT, Jones ML, Thompson K, Diette GB. The impact of inadequately controlled asthma in urban children on quality of life and productivity. Ann Allergy Asthma Immunol. 2007;98:245-251.

13. Nathan RA, Sorkness CA, Kosinski M, et al. Development of the asthma control test: A survey for assessing asthma control. J Allergy Clin Immunol. 2004;113:59-65.

14. Juniper EF, Guyatt GH, Feeny DH, Ferrie PJ, Griffith LE, Townsend M. Measuring quality of life in children with asthma. Qual Life Res. 1996;5: $35-46$.

15. Shikiar R, Halpern MT, Rentz AM, Khan ZM. Development of the Health and Work Questionnaire (HWQ): An instrument for assessing workplace productivity in relation to worker health. Work. 2004;22: 219-229.

16. Bacharier LB, Boner A, Carlsen KH, et al. Diagnosis and treatment of asthma in childhood: A PRACTALL consensus report. Allergy. 2008; 63:5-34.

17. Pauwels RA, Pedersen S, Busse WW, et al. Early intervention with budesonide in mild persistent asthma: A randomised, double-blind trial. Lancet. 2003;361:1071-1076.

18. Adams NP, Bestall JC, Lasserson TJ, Jones PW. Inhaled fluticasone versus placebo for chronic asthma in adults and children. Cochrane Database Syst Rev. 2005:CD003135.

19. Adams NP, Bestall JC, Jones PW, Lasserson TJ, Griffiths B, Cates C. Inhaled fluticasone at different doses for chronic asthma in adults and children. Cochrane Database Syst Rev. 2005:CD003534.

20. Long-term effects of budesonide or nedocromil in children with asthma. The Childhood Asthma Management Program Research Group. NEngl J Med. 2000;343:1054-1063.

21. Sharek PJ, Bergman DA. The effect of inhaled steroids on the linear growth of children with asthma: A meta-analysis. Pediatrics. 2000;106:E8.

22. Bisgaard $\mathrm{H}$. Effect of long-acting beta 2 agonists on exacerbation rates of asthma in children. Pediatr Pulmonol. 2003;36:391-398.

23. Zimmerman B, D'Urzo A, Berube D. Efficacy and safety of formoterol Turbuhaler when added to inhaled corticosteroid treatment in children with asthma. Pediatr Pulmonol. 2004;37:122-127.

24. Russell G, Williams DA, Weller P, Price JF. Salmeterol xinafoate in children on high dose inhaled steroids. Ann Allergy Asthma Immunol. $1995 ; 75: 423-428$.

25. Malone R, LaForce $\mathrm{C}$, Nimmagadda $\mathrm{S}$, et al. The safety of twice-daily treatment with fluticasone propionate and salmeterol in pediatric patients with persistent asthma. Ann Allergy Asthma Immunol. 2005;95: 66-71.

26. Simons FE, Gerstner TV, Cheang MS. Tolerance to the bronchoprotective effect of salmeterol in adolescents with exercise-induced asthma using concurrent inhaled glucocorticoid treatment. Pediatrics. 1997;99: 655-659.

27. Nelson HS, Weiss ST, Bleecker ER, Yancey SW, Dorinsky PM. The Salmeterol Multicenter Asthma Research Trial: A comparison of usual pharmacotherapy for asthma or usual pharmacotherapy plus salmeterol. Chest. 2006;129:15-26.

28. Bousquet J, Cabrera P, Berkman N, et al. The effect of treatment with omalizumab, an anti-IgE antibody, on asthma exacerbations and emergency medical visits in patients with severe persistent asthma. Allergy. 2005;60:302-308.

29. Bousquet J, Wenzel S, Holgate S, Lumry W, Freeman P, Fox H. Predicting response to omalizumab, an anti-IgE antibody, in patients with allergic asthma. Chest. 2004;125:1378-1386.
30. Humbert M, Beasley R, Ayres J, et al. Benefits of omalizumab as add-on therapy in patients with severe persistent asthma who are inadequately controlled despite best available therapy (GINA 2002 step 4 treatment): INNOVATE. Allergy. 2005;60:309-316.

31. Massanari M, Milgrom H, Pollard S, et al. Adding omalizumab to the therapy of adolescents with persistent uncontrolled moderate - severe allergic asthma. Clin Pediatr (Phila). 2009;48:859-865.

32. Ogawa Y, Calhoun WJ. The role of leukotrienes in airway inflammation. J Allergy Clin Immunol. 2006;118:789-798.

33. O'Byrne PM. Leukotriene bronchoconstriction induced by allergen and exercise. Am J Respir Crit Care Med. 2000;161:S68-S72.

34. Meltzer SS, Hasday JD, Cohn J, Bleecker ER. Inhibition of exerciseinduced bronchospasm by zileuton: A 5-lipoxygenase inhibitor. Am J Respir Crit Care Med. 1996;153:931-935.

35. Israel E, Dermarkarian R, Rosenberg M, et al. The effects of a 5-lipoxygenase inhibitor on asthma induced by cold, dry air. $N$ Engl $J$ Med. 1990;323:1740-1744.

36. Holgate ST, Peters-Golden M. Introduction: The anti-inflammatory role of cysteinyl leukotriene receptor antagonists in asthma. J Allergy Clin Immunol. 2003;111:S1-S4.

37. Lee E, Robertson T, Smith J, Kilfeather S. Leukotriene receptor antagonists and synthesis inhibitors reverse survival in eosinophils of asthmatic individuals. Am J Respir Crit Care Med. 2000;161:1881-1886.

38. Sandrini A, Ferreira IM, Gutierrez C, Jardim JR, Zamel N, Chapman KR. Effect of montelukast on exhaled nitric oxide and nonvolatile markers of inflammation in mild asthma. Chest. 2003;124:1334-1340.

39. Wahn U, Dass SB. Review of recent results of montelukast use as a monotherapy in children with mild asthma. Clin Ther. 2008;30: $1026-1035$.

40. Jartti T. Inhaled corticosteroids or montelukast as the preferred primary long-term treatment for pediatric asthma? Eur J Pediatr. 2008;167: 731-736.

41. Reiss TF, Chervinsky P, Dockhorn RJ, Shingo S, Seidenberg B, Edwards TB. Montelukast, a once-daily leukotriene receptor antagonist, in the treatment of chronic asthma: A multicenter, randomized, double-blind trial. Montelukast Clinical Research Study Group. Arch Intern Med. 1998;158:1213-1220.

42. Knorr B, Matz J, Bernstein JA, et al. Montelukast for chronic asthma in 6- to 14-year-old children: A randomized, double-blind trial. Pediatric Montelukast Study Group. JAMA. 1998;279:1181-1186.

43. Knorr B, Holland S, Rogers JD, Nguyen HH, Reiss TF. Montelukast adult (10-mg film-coated tablet) and pediatric (5-mg chewable tablet) dose selections. J Allergy Clin Immunol. 2000;106:S171-S178.

44. Spahn JD, Covar RA, Jain N, et al. Effect of montelukast on peripheral airflow obstruction in children with asthma. Ann Allergy Asthma Immunol. 2006;96:541-549.

45. Garcia Garcia ML, Wahn U, Gilles L, Swern A, Tozzi CA, Polos P. Montelukast, compared with fluticasone, for control of asthma among 6- to 14-year-old patients with mild asthma: The MOSAIC study. Pediatrics. 2005;116:360-369.

46. Sorkness CA, Lemanske RF Jr, et al. Long-term comparison of 3 controller regimens for mild-moderate persistent childhood asthma: The Pediatric Asthma Controller Trial. J Allergy Clin Immunol. 2007;119:64-72.

47. Zeiger RS, Szefler SJ, Phillips BR, et al. Response profiles to fluticasone and montelukast in mild-to-moderate persistent childhood asthma. J Allergy Clin Immunol. 2006;117:45-52.

48. Szefler SJ, Phillips BR, Martinez FD, et al. Characterization of withinsubject responses to fluticasone and montelukast in childhood asthma. J Allergy Clin Immunol. 2005;115:233-242.

49. Vaquerizo MJ, Casan P, Castillo J, et al. Effect of montelukast added to inhaled budesonide on control of mild to moderate asthma. Thorax. 2003;58:204-210.

50. Price DB, Hernandez D, Magyar P, et al. Randomised controlled trial of montelukast plus inhaled budesonide versus double dose inhaled budesonide in adult patients with asthma. Thorax. 2003;58:211-216. 
51. Laviolette M, Malmstrom K, Lu S, et al. Montelukast added to inhaled beclomethasone in treatment of asthma. Montelukast/Beclomethasone Additivity Group. Am J Respir Crit Care Med. 1999;160: 1862-1868.

52. Lemanske RF Jr, Mauger DT, Sorkness CA, et al. Step-up therapy for children with uncontrolled asthma receiving inhaled corticosteroids. N Engl J Med. 2010;362:975-985.

53. Gotshall RW. Exercise-induced bronchoconstriction. Drugs. 2002;62: 1725-1739.

54. Garcia-Aymerich J, Varraso R, Anto JM, Camargo CA Jr. Prospective study of physical activity and risk of asthma exacerbations in older women. Am J Respir Crit Care Med. 2009;179:999-1003.

55. Bisgaard H, Szefler SJ. Understanding mild persistent asthma in children: The next frontier. J Allergy Clin Immunol. 2005;115:708-713.

56. Kemp JP, Dockhorn RJ, Shapiro GG, et al. Montelukast once daily inhibits exercise-induced bronchoconstriction in 6- to 14-year-old children with asthma. J Pediatr. 1998;133:424-428.

57. Kim JH, Lee SY, Kim HB, et al. Prolonged effect of montelukast in asthmatic children with exercise-induced bronchoconstriction. Pediatr Pulmonol. 2005;39:162-166.

58. Verhoeff NP, Speelberg B, van den Berg NJ, Oosthoek CH, Stijnen T. Real and pseudo late asthmatic reactions after submaximal exercise challenge in patients with bronchial asthma. A new definition for late asthmatic responses after exercise challenge. Chest. 1990;98: 1194-1199.

59. Karjalainen J. Exercise response in 404 young men with asthma: No evidence for a late asthmatic reaction. Thorax. 1991;46:100-104.

60. Lee TH, Nagakura T, Papageorgiou N, Iikura Y, Kay AB. Exerciseinduced late asthmatic reactions with neutrophil chemotactic activity. N Engl J Med. 1983;308:1502-1505.

61. Boulet LP, Legris C, Turcotte H, Hebert J. Prevalence and characteristics of late asthmatic responses to exercise. J Allergy Clin Immunol. 1987;80:655-662.

62. Melo RE, Sole D, Naspitz CK. Exercise-induced bronchoconstriction in children: Montelukast attenuates the immediate-phase and late-phase responses. J Allergy Clin Immunol. 2003;111:301-307.
63. McAlpine LG, Thomson NC. Prophylaxis of exercise-induced asthma with inhaled formoterol, a long-acting beta 2-adrenergic agonist. Respir Med. 1990;84:293-295.

64. Anderson SD. Single-dose agents in the prevention of exercise-induced asthma: A descriptive review. Treat Respir Med. 2004;3:365-379.

65. Garcia R, Guerra P, Feo F, et al. Tachyphylaxis following regular use of formoterol in exercise-induced bronchospasm. J Investig Allergol Clin Immunol. 2001;11:176-182.

66. Booth H, Bish R, Walters J, Whitehead F, Walters EH. Salmeterol tachyphylaxis in steroid treated asthmatic subjects. Thorax. 1996;51:1100-1104.

67. Edelman JM, Turpin JA, Bronsky EA, et al. Oral montelukast compared with inhaled salmeterol to prevent exercise-induced bronchoconstriction. A randomized, double-blind trial. Exercise Study Group. Ann Intern Med. 2000;132:97-104.

68. Leff JA, Busse WW, Pearlman D, et al. Montelukast, a leukotrienereceptor antagonist, for the treatment of mild asthma and exerciseinduced bronchoconstriction. N Engl J Med. 1998;339:147-152.

69. Helenius I, Lumme A, Ounap J, et al. No effect of montelukast on asthmalike symptoms in elite ice hockey players. Allergy. 2004;59:39-44.

70. Lima JJ, Zhang S, Grant A, et al. Influence of leukotriene pathway polymorphisms on response to montelukast in asthma. Am J Respir Crit Care Med. 2006;173:379-385.

71. Tantisira KG, Drazen JM. Genetics and pharmacogenetics of the leukotriene pathway. J Allergy Clin Immunol. 2009;124:422-427.

72. Kang MJ, Lee SY, Kim HB, et al. Association of IL-13 polymorphisms with leukotriene receptor antagonist drug responsiveness in Korean children with exercise-induced bronchoconstriction. Pharmacogenet Genomics. 2008; 18:551-558.

73. Bousquet J, Khaltaev N, Cruz AA, et al. Allergic Rhinitis and its Impact on Asthma (ARIA) 2008 update (in collaboration with the World Health Organization, GA(2)LEN and AllerGen). Allergy. 2008;63 Suppl 86: 8-160.

74. Price DB, Swern A, Tozzi CA, Philip G, Polos P. Effect of montelukast on lung function in asthma patients with allergic rhinitis: Analysis from the COMPACT trial. Allergy. 2006;61:737-742.
Adolescent Health, Medicine and Therapeutics

\section{Publish your work in this journal}

Adolescent Health, Medicine and Therapeutics is an international, peer-reviewed, open access journal focusing on health, pathology, and treatment issues specific to the adolescent age group. All aspects of health maintenance, preventative measures and disease treatment interventions are addressed within the journal and practitioners from

\section{Dovepress}

all disciplines are invited to submit their work as well as healthcare researchers and patient support groups.. The manuscript management system is completely online and includes a very quick and fair peerreview system. Visit http://www.dovepress.com/testimonials.php to read real quotes from published authors. 